BULLETIN Bulletin hispanique

HISPANIQUE Université Michel de Montaigne Bordeaux

119-1 | 2017

Autorité et pouvoir dans le théâtre du Siècle d'Or

\title{
Los personajes femeninos en Calderón
}

Su autoridad y poder en la vida privada y pública

\section{Christoph Strosetzki}

\section{(2) OpenEdition}

\section{Journals}

Edición electrónica

URL: http://journals.openedition.org/bulletinhispanique/4916

DOI: 10.4000/bulletinhispanique.4916

ISBN: 979-10-300-0142-6

ISSN: $1775-3821$

Editor

Presses universitaires de Bordeaux

Edición impresa

Fecha de publicación: 15 junio 2017

Paginación: 271-284

ISBN: 979-10-300-0141-9

ISSN: 0007-4640

Referencia electrónica

Christoph Strosetzki, «Los personajes femeninos en Calderón », Bulletin hispanique [En línea], 119-1 | 2017, Publicado el 15 junio 2020, consultado el 18 septiembre 2020. URL : http://

journals.openedition.org/bulletinhispanique/4916; DOI : https://doi.org/10.4000/bulletinhispanique. 4916

Tous droits réservés 


\section{Los personajes femeninos en Calderón: Su autoridad y poder en la vida privada y pública}

\section{Christoph STROSETZKI \\ Universität Münster}

Au regard des traités, largement répandus, d'éducation à l'usage des femmes, comme la Instrucción de la mujer cristiana de Juan Luis Vives, se pose la question de savoir si les figures féminines des drames de Calderón suivent les règles qui y sont indiquées. Si les reines chez Calderón ne bénéficient jamais d'un pouvoir illimité, les épouses, en échange, ne sont ni sans volonté ni totalement passives.

Mots-clés: autorité, pouvoir, traité d'éducation, miroir des princes, souveraine, épouse, Calderón, honneur.

A la vista de los ampliamente extendidos manuales de conducta tales como la Instrucción de la mujer cristiana de Juan Luis Vives, surge la pregunta de si también los personajes femeninos de Calderón siguen las normas propuestas. Ni las reinas tienen en las obras de Calderón un poder ilimitado ni carecen las mujeres casadas de voluntad propia no siendo, por tanto, completamente pasivas.

Palabras clave: autoridad, poder, manuales de conducta, espejo de príncipes, soberana, esposa, Calderón, honra.

Considering the widley spread treatises on how to behave, as for example the "Instrucción de la mujer cristiana" by Juan Luis Vives, the question arises whether in Calderón's plays also the female characters follow the suggested rules. In Calderón, neither female monarchs have unconditional power, nor wives are completely weakwilled and passive.

Keywords: authority, power, treatises on education, mirror for princes, female monarch, wife, Calderón, honour. 
G I humanista español Juan Luis Vives escribió a comienzos de la edad C moderna críticos tratados teórico-científicos para cambiar el sistema científico de su tiempo, al cual le reprochaba estar demasiado orientado en el modelo escolástico. Tematizando la institución del matrimonio, sin embargo, continuaba estando profundamente comprometido con la tradición. El tratado educativo de Vives De institutione feminae christianae (1523) estuvo hasta finales del siglo XVI muy extendido en Europa con más de cuarenta ediciones y traducciones. En tres libros se recogen: primero, explicaciones sobre la doncella, después, sobre la mujer casada y, finalmente, sobre la viuda. Vives recurre en sus exposiciones a la tradición de la literatura didáctica de Jenofonte, Aristóteles, Platón, Tertuliano, Hierónimo, Agustín y Fulgencio. Para la doncella Vives exige una instrucción práctica basada en tareas del hogar, como hilar lana y lino y cocinar, al mismo tiempo que una instrucción teórica que incluye primero aprender a leer y a escribir la lengua vernácula antes de pasar a continuación al latín. La base de la virtus es la sapientia. Esta última se consigue a través de la lectura de libros selectos. La virginidad y la castidad son preceptos fundamentales para la mujer joven.

La mujer tiene que estar sometida a su futuro marido. Vives demuestra con un ejemplo del libro 12 de la Eneida de Virgilio, que son los padres los que tienen que aconsejar a la hija en la elección del futuro marido. El papel de la hija es dejarlo todo a su cargo y no intervenir. Además, la hija misma no puede desear a ningún hombre en concreto, pero si tuviera predilección por alguno, entonces no deberá decírselo a nadie "porque en la doncella el tal deseo no carece de una cierta especie de deshonestidad $»^{1}$. Todo tiene que estar muy bien pensado, pues «el casamiento es un nudo, que ni se deja ni se rompe; solo por mano de la muerte se ha de desatar $\aleph^{2}$. Si Vives contempla la riqueza en el matrimonio, esta será duradera solo en el caso de que sea sostenida por virtudes. Diligencia y templanza crean y mantienen la riqueza, mientras que negligencia y desconcierto, en cambio, la destruyen, especialmente cuando se les une la soberbia y la ambición. Mientras que continuamente unos se enriquecen y otros empobrecen, lo importante no es la fortuna obtenida por casualidad sino los valores como la moral y la disciplina. Según Vives las cosas más importantes que una mujer puede llevar al matrimonio son entera castidad y buena fama. Por ello Vives considera un error que las hijas casaderas salgan mucho, que hablen o que vayan a bailar con mucha gente para conocer más fácilmente a posibles futuros maridos o para aprender a tratarlos. Pues, ¿quién puede preservar mejor la castidad y la buena fama: aquella que se queda en casa y no tiene ocasión de comportarse de forma errónea o aquella que encuentra en público numerosas oportunidades? Mientras que no hay ocasión de que se levanten habladurías sobre la primera, la segunda, sin embargo, es objeto de

1. Juan Luis Vives, Instrucción de la mujer cristiana, Buenos Aires, Espasa Calpe, 1948, p. 128.

2. Ibid., p. 129. 
toda clase de difamaciones, simplemente por el hecho de que quizá parezca que sean fundadas. A la que, según Vives, más se tiene que alabar es a aquella que no aparece nunca o casi nunca en público. Se la puede comparar con una piedra preciosa, a la que la naturaleza mantiene oculta, mientras que las cosas cotidianas se pueden encontrar por todas partes. Se ha mostrado, por tanto, que Vives dispone de numerosas reglas; asimismo, le son más importantes las virtudes que la riqueza o la alcurnia. Virginidad y castidad las toma como máximos axiomas de los que deriva la necesidad de que la doncella lleve una vida de recogimiento y rehúya la vida social, para evitar en última instancia que surjan rumores.

Podríamos calificar como pasiva aquella forma de vida que evita el aparecer en público, siendo en este caso el replegarse en la propia casa una eficaz medida de prevención frente a peligrosas tentaciones. Más peligroso aún ha de parecernos por lo tanto el que, tal y como ocurre en El médico de su honra de Calderón, sea la tentación la que llame a la puerta en forma de antigua amante. ¿Es posible en este caso permanecer acaso impasible y eludir además toda sospecha? ¿O se vislumbra quizás la tragedia ya en el mismo acto de abrir la puerta? Observemos por tanto brevemente el argumento de la obra.

De camino a Sevilla el infante Enrique se cae del caballo y pierde el sentido. Sus acompañantes lo llevan a una casa de campo cercana. Cuando vuelve en sí, reconoce en la anfitriona Mencía a su antiguo amor. Al mirarla se siente feliz. Pero se desilusiona cuando descubre que mientras tanto ella se ha casado con Gutierre. Con este prosigue su viaje a Sevilla. Mencía le cuenta a su criada Jacinta que hace tiempo había sido cortejada por el Infante y solo cuando este se hubo ausentado durante mucho tiempo se había casado con Gutierre. Leonor se lamenta ante el rey en Sevilla de que Gutierre le había prometido casarse con ella y, debido a que este no había cumplido, ella había sido deshonrada.

Enrique aprovecha la próxima oportunidad para visitar a Mencía. Apenas tiene ocasión de lamentarse sobre su horrible destino, cuando ya regresa Gutierre. Enrique se esconde. Mencía se siente culpable y sorprendida haciendo algo prohibido aunque nada había ocurrido. Gutierre comienza a sospechar porque Mencía le habla de un desconocido que ha irrumpido en la casa. En un acto irreflexivo ella apaga la luz, para posibilitar la fuga de Enrique, que con las prisas pierde su puñal. Gutierre, que ha encontrado el puñal, se lo lleva al rey al día siguiente y después de haber escuchado por casualidad una conversación en la que Enrique le confiesa al rey su amor por Mencía, llega a la conclusión de que Enrique es el dueño del puñal y el amante de su mujer. Cuando Mencía se entera de que Enrique ha abandonado el país enfermo de amor por ella y de que el rey está desolado por este motivo, ella se decide a escribirle una carta. La carta comienza así:

\footnotetext{
Vuestra Alteza, señor... (iQue por alteza vino mi honor a dar a tal bajeza!) ...no se ausente... ${ }^{3}$
}

3. Pedro Calderón de la Barca, El médico de su honra, Ana Armendáriz Aramendía ed., Madrid/Frankfurt, Iberoamericana, 2007 (BAH 40), p. 465, vv. 2462-2464. 
Cuando Gutierre lee sin querer estas líneas las malinterpreta como una invitación a un encuentro amoroso y se convence de la culpa de su mujer. Su condenación definitiva la realiza finalmente Gutierre por escrito: «El amor te adora, el honor te aborrece; y así el uno te mata, y el otro te avisa: dos horas tienes de vida; cristiana eres, salva el alma, que la vida es imposible» ${ }^{4}$.

Toda contradicción y pronunciamiento resultan imposibles. Por encargo de Gutierre el quirurgo Ludovico mata a Mencía realizándole una sangría. Gutierre quiere invalidar como testigo al quirurgo, puesto que tiene la intención de culparle de la muerte de su mujer. El rey, sin embargo, lo examina, reconoce que Gutierre ha obrado por venganza y ordena que el perplejo «médico de su honra» se case con su anterior amada, Leonor. El compromiso matrimonial es sellado con mano ensangrentada. Que este matrimonio sea una justicia con misericordia y que Gutierre cumpla su compromiso con Leonor, adquirido pero no cumplido, no permite ciertamente ver el final como castigo de Gutierre pero tampoco como un happy end.

Mencía se había casado con Gutierre tras haber creído que su amado Enrique había muerto en la guerra. Sin embargo, cuando Enrique se presenta ante ella de manera inesperada, comienza para ella un combate entre unos sentimientos todavía existentes y su conciencia del deber:

$$
\begin{aligned}
& \text { ¡Aquí fue amor! } \\
& \text { Mas ¿qué digo? } \\
& \text { ¿Qué es esto, cielos, qué es esto?? }
\end{aligned}
$$

Pero dado que Mencía no se encuentra en posición de vencer por completo sus sentimientos se ve inmiscuida por su comportamiento en situaciones que comprometen su honra. Oculta al hombre de su corazón del guardián de su honor y comete un error tras otro sin, por ello, serle infiel a Gutierre con Enrique. Sus sentimientos de culpa muestran que es consciente de la transgresión de las fronteras sociales:

$$
\begin{aligned}
& \text { Así yo, viendo a tu Alteza } \\
& \text { quedé muda, absorta estuve, } \\
& \text { conocí el riesgo y temblé; } \\
& \text { tuve miedo, y horror tuve }
\end{aligned}
$$

Con respecto a Enrique ella actúa de manera activa y toma la iniciativa, la primera falta que comete, ya antes de su matrimonio, consiste en que no pone su relación anterior en conocimiento de Gutierre. También surge la cuestión de si debería haberle concedido refugio a Enrique o de si se lo podría haber

4. Ibid., p. 466 (fuera de la numeración, entre los versos 2495 y 2496).

5. Ibid., p. 347, vv. 131-132.

6. Ibid., p. 401, vv. 1129-1132. 
negado. Finalmente ella debería haberle dejado marchar y no haber insistido, con sus reiterados ruegos, en que se quedara:

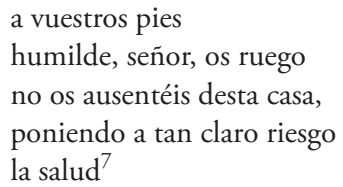

Ella alimenta sus esperanzas mediante el anuncio de una disculpa por su parte:

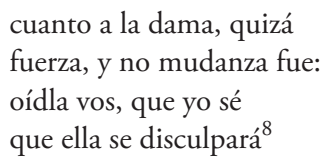

Cuando tiene lugar esta cita Enrique es consciente del hecho de que la iniciativa ha partido de Mencía:

Esto es tomar tu consejo.

Tú me aconsejas que escuche

disculpas de aquella dama ${ }^{9}$

Cuando la conversación entre ambos se ve interrumpida por la llegada del marido, Mencía urge a Enrique para que se esconda. Esto no habría sido necesario puesto que la presencia de Enrique podría haber sido explicada también como una visita oficial de agradecimiento. Este se muestra también sorprendido y solo reacciona después de que se le solicite de manera repetida e insistente: «¿Yo me tengo de esconder?» A lo cual responde Mencía:

El honor de una mujer a más de esto ha de obligaros ${ }^{10}$

Las explicaciones falsas de Mencía resultan inverosímiles y tienen que despertar desconfianza, sobre todo al verse seguidas de una especie de disculpa:

Un hombre $[\ldots]$ escondido en mi aposento he topado, encubierto y rebozado.

Favor, Gutierre, te pido" 11

El análisis formal de las frases hechas demuestra que la relación entre Mencía y Gutierre a duras penas podría ser más fría. Mientras que entre Mencía y

7. Ibid., p. 356, vv. 309-313.

8.Ibid., p. 361, vv. 421-424.

9. Ibid., p. 399, vv. 1091-1093.

10. Ibid., p. 402, vv. 1152-1154.

11. Ibid., p. 410, vv. 1297-1300. 
Enrique domina un mayor desenfado y espontaneidad. Cuando Mencía le cuenta en pocas palabras a Jacinta su vida, se rememora el relato de una enfermedad en el que se investigan las causas de su tristeza:

$$
\begin{aligned}
& \text { Nací en Sevilla, y en ella } \\
& \text { me vio Enrique, festejó } \\
& \text { mis desdenes, celebró } \\
& \text { mi nombre, felice estrella! } \\
& \text { Fuese, y mi padre atropella } \\
& \text { la libertad que hubo en mi: } \\
& \text { la mano a Gutierre di } \\
& \text { volvió Enrique, y en rigor, } \\
& \text { tuve amor, y tengo honor: } \\
& \text { esto es cuanto sé de mí”12 }
\end{aligned}
$$

Queda claro el recuerdo nostálgico de unos tiempos mejores en Sevilla. Según Lauer ${ }^{13}$ el pasado de Mencía, condicionado por la abstinencia amorosa, es ya histérico, de modo que ella se habría casado con Gutierre sin amarlo, lo que explicaría el trato formal entre ellos. Lauer responsabiliza a la reaparición del amado dado por perdido de múltiples síntomas, como por ejemplo: falsas acusaciones, pena de amor, fluctuaciones del carácter y redundancia del discurso. $Y$ es que es evidente que, pese a haberse comportado Mencía aparentemente de forma pasiva siguiendo a rajatabla las exigencias de Vives de no salir de casa, la sospecha de la infidelidad se levanta sobre ella. Pero mirando de cerca se ha mostrado que Mencía influye activamente en la acción y tiene el poder de modelarla en función de sus deseos.

En las piezas de Calderón que trataremos a continuación las mujeres se escapan del ámbito de lo privado, presentándose en público y ocupando por tanto un rol cuando menos activo. No obstante se nos plantea la duda de en qué medida les estará permitido realmente a las mujeres ocupar el papel del hombre, siendo también importante plantearse el si tendrán estas quizás que echar mano de medios típicamente femeninos para adueñarse de una esfera de poder reservada aparentemente a los hombres.

Así Ana Bolena empujará al rey Enrique VIII a divorciarse de su mujer Catarina en La cisma de Inglaterra. Debido a que esa separación sólo será posible a través de la división de la iglesia inglesa de la romana, será Ana quien en última instancia aparezca como responsable del cisma de Inglaterra, siendo evidente que no sale con ello su personaje muy bien parado en lo que a la división del bien y del mal se refiere. No obstante, y ya que a fin de cuentas el culpable no deja de ser el rey Enrique que bien podría haber resistido la seducción y tentación de Ana, no podrá este tampoco ser considerado como

12. Ibid., p. 369, vv. 565-574.

13. Robert A. Lauer, "La enfermedad y la cura de Mencía en El médico de su honra de Calderón», en Calderón. Protagonista eminente del Barroco europeo, vol. 1, Kassel, Reichenberger, 2000, pp. 281-294, p. 289 
contrafigura masculina positiva. Por el contrario la princesa María sí aparece en el polo de lo positivo como verdadera heredera del trono al oponerse al rey cuando este exige de ella su permiso para expropiar los bienes de la iglesia católica en Inglaterra.

Por otro lado en La gran Cenobia la reina Cenobia vencerá a las tropas romanas de Decio, lo cual tendrá como consecuencia el escarnio de Decio por parte de un Aureliano recién erigido como emperador romano. Este último protagonizará a su vez una exitosa contraofensiva cuyo resultado será el llevar a Cenobia cautiva a Roma. Sin embargo, y antes de que Cenobia logre vencer la arrogancia de Aureliano fingiendo un falso amor, será este asesinado por Decio. El pueblo celebrará el tiranicidio erigiendo a Decio como emperador y este hará lo mismo al hacer de Cenobia su emperatriz. Cenobia se presenta por tanto primero como vencedora y adversaria de Roma. Luego, sin embargo, al ser cautiva de Aureliano, no le quedará sino tirar de sus armas de mujer, debiendo, no obstante, el final feliz a un Decio que la elevará a la categoría de emperatriz.

En Afectos de odio y amor Cristerna es reina de Suecia y adversaria de Rusia; el duque ruso Casimiro, que ha matado al monarca de Suecia en el campo de batalla, ha caído rendido a los pies de ella, razón por la cual se infiltrará en la corte sueca de incógnito pasando a ocupar altos cargos rápidamente. La obra termina al ser este desenmascarado y pasar a celebrarse, acto seguido, los desposorios con Cristerna, la cual comenta:

$$
\begin{aligned}
& \text { Estése } \\
& \text { el mundo como se estaba, } \\
& \text { y sepan que las mujeres } \\
& \text { vasallas del hombre nacen; } \\
& \text { pues en sus afectos, siempre } \\
& \text { que el odio y amor compiten, } \\
& \text { es el amor el que vence."14 }
\end{aligned}
$$

Tomás Boleno se dirige a su hija, Ana Bolena, en el primer acto de La cisma de Inglaterra, de modo que sus palabras se erigen como frontispicio de los hechos que se van a desarrollar en la comedia:

$$
\begin{aligned}
& \text { Ana, ya estás en palacio; } \\
& \text { agora en tu mano tienes } \\
& \text { el inconstante albedrío } \\
& \text { de la fortuna y la suerte. } \\
& \text { [...] yo he hecho lo que he podido, } \\
& \text { haz tú ahora lo que debes."15 }
\end{aligned}
$$

14. Pedro Calderón de la Barca, Afectos de odio y amor, edición digital de Cervantes Virtual a partir de la Tercera parte de Comedias de don Pedro Calderón de la Barca, Madrid, por Domingo García Morràs, a costa de Domingo Palacio y Villegas, 1664. http://www.cervantesvirtual.com/ obra/afectos-de-odio-y-amor--0/, III, v. 1154-1160.

15. Pedro Calderón de la Barca. La cisma de Inglaterra, Madrid, Castalia, 1981, p. 103. 
Esta confrontación de la mujer con el ámbito del poder real va a ser un motivo constante en las comedias de Calderón. La cercanía al rey y la subsiguiente obtención de poder real, aspectos que pueden ser buscados activamente o recibidos de un tercer personaje debido a las circunstancias de la trama, van a permitir que la mujer adquiera un poder político que en la época quedaba fuera de su alcance, pudiendo usar éste a favor de un recto gobierno o, por el contrario, supeditarlo a las pasiones y los afectos.

Tomando como ejemplo las comedias La gran Cenobia, Afectos de odio y amor y La cisma de Inglaterra, puede observarse cómo los personajes femeninos cercanos al rey usan ese poder real de forma activa o de forma pasiva. Todas las protagonistas femeninas en dichas obras son o pueden llegar a ser reinas; sin embargo, unas responden a su situación activamente, mientras que otras tienen un papel pasivo en la trama. La mujer activa será aquella mediante cuyas intervenciones se altere sustancialmente el argumento de la obra. Dado que con frecuencia la mujer en la obra de Calderón tiene el poder de conmover a los personajes, debemos distinguir entre mujeres que alteran la trama con su sola presencia y mujeres que mediante la acción reconducen los acontecimientos. Éstas últimas serán las que se van a analizar aquí.

Reinas como Cenobia, Cristerna y Auristela en las comedias seleccionadas son ejemplos claros de esta mujer activa. Las tres asumen el poder real y, además, son imagen de la mujer guerrera, que, venciendo los tópicos sobre la naturaleza femenina, es constante en su defensa de la patria, gobernando y enfrentando conflictos bélicos en lugar o al lado del hombre. Junto a ellas, otra reina activa, Ana Bolena, a quien observamos en su periplo de ascenso y caída en desgracia, no ostenta el poder real sino que, como reina consorte, maneja al hombre que gobierna; esta imposibilidad de ejercer el poder de forma directa no impide que sus acciones conduzcan al desenlace más grave de los planteados en las comedias seleccionadas, el cisma de Inglaterra. Como reinas guerreras, Cenobia y Cristerna son descritas con atributos relacionados con la guerra: Cenobia ampara sus territorios con «bélico furor, marcial desvelo» ${ }^{16} \mathrm{y}$ «ánimo belicoso» ${ }^{17}$, mientras que Cristerna aparece como "sañudamente fiera»" ${ }^{18}$, además de preferir Calderón las referencias a cualidades masculinas, relacionadas con la acción, hasta el punto de adjudicar a Cristerna un «ánimo varonil $»^{19}$, mientras que cualidades femeninas, como la belleza, aunque presentes, pasan a un segundo plano:

Es Cristerna tan altiva que le sobra la belleza" ${ }^{20}$.

16. Pedro Calderón de la Barca, La gran Cenobia, en Comedias, I, Madrid, Fundación José Antonio de Castro, 2006, pp. 319-320.

17. Ibid., p. 344 .

18. Calderón de la Barca, Afectos de odio y amor, I, v. 400.

19. Ibid., III, v. 97.

20. Ibid., I, v. 275. 
Cenobia, imagen del dominio de las pasiones y del buen gobierno, defiende el reino de Palmira en lugar de su marido Abdenato, quien está impedido debido a su avanzada edad. Calderón elogia el buen gobierno de la reina, que aparece presentada por Casimiro mediante la imagen típica del caballo bien dirigido: tan firme que en un caballo que creyera que a los dos un espíritu regía, porque mostraba, aunque de furia lleno, que se pudiera gobernar sin freno; tan obediente, el céfiro animado corre igual, para fácil, veloz sube, que parece, en los vientos engendrados, hijo sutil de un rayo y de una nube ${ }^{21}$. Como señala Ignacio Arellano, «[e]mblema de fuerte sentido político y moral es el del caballo, bien regido con freno y riendas (símbolo de la prudencia) o desbocado (símbolo de la ceguera pasional, insitucional y moral) ${ }^{22}$, contrastando la alabanza de Cenobia con el caballo desbocado de Rosaura en La vida es sueño. Para defender el reino, Cenobia resiste los ataques de Aureliano y busca su derrota con el objetivo de poner fin a la contienda ${ }^{23}$, acción que impide Decio al privilegiar su propio honor sobre el éxito de Cenobia en la contienda. Al fracasar el intento de imponerse mediante las armas, hecha prisionera, Cenobia cambia los recursos masculinos de la lucha por los femeninos, recurriendo al fingimiento de amor como medio de doblegar a Aureliano: «AAhora sí que soy mujer! $»^{24}$, exclama al trocar el uso de las armas por el uso de la belleza.

A la coronación de Cristerna asistimos también al comienzo de Afectos de odio y amor. Igual que Cenobia, quien sustituye en la acción al rey, tras cuyo fallecimiento queda erigida reina, Cristerna asume el reinado de Suecia tras la muerte de su padre, el rey Adolfo, en la batalla, sustituyéndole también en la responsabilidad de defender el territorio de su patria. Mujer activa no sólo por el ejercicio práctico de su reinado, Cristerna se nos muestra como legisladora y defensora de la mujer activa, reclamando su participación en tareas tradicionalmente masculinas:

\author{
Quiero empezar a mostrar \\ si tiene o no la mujer \\ ingenio para aprender, \\ juicio para gobernar \\ y valor para lidiar; \\ y así, porque no presuma
}

21. Calderón de la Barca, La gran Cenobia, p. 322.

22. Ignacio Arellano, «Aspectos emblemáticos en los dramas de poder y de ambición de Calderón», en Ignacio Arellano (ed.), Calderón 2000. Homenaje a Kurt Reichenberger en su 80 cumpleaños, vol. II, Kassel, Reichenberger, 2002, pp. 21-34, p. 28.

23. «Siguiendo vengo a Aureliano, / resuelta animosamente/ de que hoy en su misma tienda/ he de matarle o prenderle», Pedro Calderón de la Barca, La gran Cenobia, p. 357.

24. Ibid., p. 382. 
Ingenio, juicio y valor aparecen como cualidades asociadas al buen gobierno y hasta el momento pertenencientes a la esfera del hombre. Cristerna realiza una defensa de la mujer pretendiendo mostrar en su persona cómo dichas cualidades no son ajenas a su sexo. Si el valor lo ha demostrado en la batalla, el ingenio y el juicio lo evidencian en la promulgación de leyes que incrementen la libertad de la mujer. De ahí su prohibición de los matrimonios desiguales sutentados únicamente en el amor, «aversión hacia el matrimonio, no por cuestiones religiosas, como en La protestación de la fe, sino para evitar convertirse en vasalla del hombre» ${ }^{26}$.

Este mismo aspecto nos sirve para reflexionar sobre el hombre o la mujer de Estado. Como apunta Cristerna, para un buen gobierno es necesaria la espada pero también la pluma, lo que le lleva a compararse a sí misma con César ${ }^{27}$. Esta segunda variante de la acción, mediante la palabra, la cumplen Cenobia con la composición de su Historia oriental y Cristerna con la promulgación de nuevas leyes.

Siguiendo con los personajes femeninos de Afectos de odio y amor, Auristela, hermana de Casimiro, debe hacerse responsable de Rusia cuando su hermano desaparece, pues, enamorado de Cristerna, se ha disfrazado de soldado. Auristela comparte con Cenobia y Cristerna la caracterización varonil y el valor ante un conflicto bélico:

\author{
cuando mi orgullo ciego, \\ talando a sangre y fuego \\ entre, desde la encina hasta la cańa, \\ el próvido verdor de la campańa, \\ sin perdonar el bélico tributo, \\ ni hoja, ni mies, ni vid, ni flor, ni fruto. ${ }^{28}$
}

Auristela va a ser la depositaria de las virtudes de gobierno que su hermano ha abandonado en su huida - prudencia, constancia ${ }^{29}-$ y quien le recrimina que

25. Calderón de la Barca, Afectos de odio y amor, I, vv. 647-656.

26. Ana Zúńiga Lacruz, «El poder de la reina en el teatro del Siglo de Oro. La figura de Cristina de Suecia», en El universo simbólico del poder en el Siglo de Oro, ed. Á. Baraibar y M. Insúa, Nueva York/Pamplona, Instituto de Estudios Auriseculares (IDEA)/Servicio de Publicaciones de la Universidad de Navarra, 2012, pp. 331- 339, p. 335.

27. Calderón de la Barca, Afectos de odio y amor, I, v. 664.

28. Calderón de la Barca, Afectos de odio y amor, II, vv. 543-548.

29. Dice Casimiro de Auristela (Calderón de la Barca, Afectos de odio y amor, II, vv. 10561061):

No sé cómo,

Turín, pueda haberse hallado, 
por amor esté faltando a las obligaciones de su patria. Frente a la indecisión de Casimiro, Auristela provoca el desenlace de la comedia descubriendo ante Cristerna cómo aquél dio muerte a su padre Adolfo, lo que le vale recibir el calificativo de traidora -alta traicion, pues está entregando a su hermano y soberano a una reina enemiga-, pero, sin embargo, le permite lograr mediante una inteligente estratagema la salvación del mismo. Al entregarlo, recibe en premio la mano de Auristela, mano que cede a su hermano, de forma que las bodas entre Casimiro y Cristerna pueden tener lugar sin violentar el honor de ninguno de los dos. Auristela permite el final feliz al uso mediante su ingeniosa solución.

Frente a estas mujeres que acceden al gobierno real de manera legítima, Ana Bolena, desencadenante del conflicto de La cisma de Inglaterra, lleva a cabo un asalto al poder real. Sus armas, en este caso, serán las típicamente femeninas, es decir, su belleza y su amor, y su ámbito de acción no estará en el espacio de la guerra sino en el de la palabra. Esta última diferencia se manifiesta prontamente , pues en sus primeras apariciones Ana Bolena se nos presenta como un ejemplo de mujer pasiva. Tanto al comienzo de la obra, como sombra que inquiera a Enrique VIII, como con el baile que le sirve de presentación ante los reyes, Ana tan solo se muestra; no obstante, es su mera presencia el desencadenante de la acción, en tanto que trastoca al rey desde el primer momento. La importancia del personaje parece clara desde el inicio de la obra, donde las imágenes clásicas de la «sombra», el «sol eclipsado» o la «deslucida estrella» adelantan la influencia que tendrá en el gobierno del rey.

Sin embargo, el papel activo de Ana Bolena se va a ir desvelando desde el principio. Una vez presentada en palacio, la joven va a tratar de convertirse en reina, lo que va a conseguir mediante la seducción por medio de la belleza y a partir del uso de la palabra como arma ${ }^{30}$, mediante la cual manipula a Enrique VIII para otorgar cargos religiosos, apartar a Volseo, eliminar los derechos sucesorios de la infanta María y herir a la reina Catalina ${ }^{31}$, todo ello disimulado ante el rey como ejercicio de sus virtudes.

Calificada como «reina tirana» por Volseo ${ }^{32}$, Bolena no logra acordar los afectos y el buen gobierno, lo que conduce a la desgracia del rey, del reino y de su persona. Este mismo conflicto, pero en dirección opuesta, es el que lleva a

ni una mujer tan prudente,
ni un hombre tan desdichado,
que ella se alce con el nombre
de constante, y él de vario.

30. No deja de ser paradójico que Volseo haya alentado el deseo de Bolena de convertirse en reina también por medio de la palabra, tentándola al llamarla intencionadamente por error Majestad (Calderón de la Barca. La cisma de Inglaterra, p. 131).

31. Un ejemplo claro de esta acción que se lleva a cabo por medio de la palabra son los siguientes versos: «Yo veré/ la carta. (Y será porque en ella ponga veneno.)», Calderón de la Barca, ibid., p. 164.

32. Calderón de la Barca, ibid., p. 162. 
Cristerna, en su afán por gobernar rectamente, a promulgar su conflictiva ley de matrimonio. Cristerna vincula erróneamente los afectos a la razón de estado cuando proclama que ninguna mujer se ha de casar sólo por amor, ley que finalmente debe retirar pues debe haber acuerdo entre las pasiones y la razón de estado para que pueda darse un correcto gobierno político. Cuando la pasión nubla el entendimiento (en Ana Bolena la ambición, en Enrique VIII el amor) o cuando el poder pretende esquivar los afectos (Cristerna) el buen gobierno se desvía.

Para terminar, podemos señalar cómo, pese a las grandes figuras de reinas estudiadas, la restitución del orden natural llega siempre con el gobierno masculino. Esta consideración se encarna claramente en la equiparación de dos reyes, positivo y negativo, a partir de recursos simbólicos en La gran Cenobia. Decio es quien al final de la comedia vence a Aureliano y quien le sustituye. Como señala Ignacio Arellano, ambos, Aureliano al principio y Decio al final, han sido coronados con el "sagrado laurel», símbolo de poder de gran éxito en la emblemática, igual que las águilas de Roma que aparecen en el escudo de Decio y en el anillo de Aureliano ${ }^{33}$. Los dos reyes están relacionados entre sí mediante los símbolos políticos y por su posición en la obra, pues uno es coronado al inicio y otro al final. El espacio intermedio entre ambos es el que ocupa Cenobia, quien, como Cristerna, sólo se encarga de la dirección del reino hasta un posterior restablecimiento del rey. La mujer activa aparece, entonces, como complemento de la posición desviada del hombre, que está o bien muerto o ausente (reinas Cenobia, Cristerna, Auristela), o enajenado (Enrique VIII).

En conclusión, las reinas presentadas eluden la superficialidad de la caracterización típica femenina para sustentarse en valores y actitudes netamente masculinos, sin dejar de lado tampoco sus defectos. Cristerna, Auristela, Cenobia y Ana Bolena aparecen puntualmente como tiranas, se confían a consejeros inapropiados e incurren en defectos de gobierno como la alta traición que lleva a Auristela a entregar a su hermano o la razón de estado que mueve a Cristerna a condenar los matrimonios desiguales. Asimismo, el fingimiento (Cenobia), y el disimulo (Auristela) se plantean como medios que permiten obtener el deseado fin del buen gobierno.

En cuanto a la dinámica de género, la mujer activa en Calderón por un lado sustituye temporalmente al hombre en su papel de gobernante y guerrero, mientras que por otro influye en él mediante la acción no directa de la palabra. En ambos casos, como señala Juan de Mariana en Del rey y de la institución de la dignidad real ${ }^{34}$, el papel del amor y de los afectos incide en el buen gobierno, lo

33. Ignacio Arellano, op. cit., pp. 22-23.

34. «[P]ara juzgar es menester hallarse exento de odio, de amor, y de ira, y de todos los demás afectos que perturban el ánimo y que son la causa principal de haber establecido las leyes», Juan de Mariana, Del rey y de la institución de la dignidad real, Madrid, Imprenta de la Sociedad Literaria y Tipográfica, 1845, p. 31. 
que hace necesaria la existencia de un «arte amatorio político» ${ }^{35}$ que armonice ambos factores. Evidentemente, no encontraremos en las obras dramáticas de Calderón a mujeres pasivas e inactivas. Como hemos visto, ni siquiera Mencía en El médico de su honra podría ser considerada una mujer recatada tal y como lo entendía Juan Luis Vives, ya que esta, con su acción, contribuye al desenlace trágico final. Por otra parte, se hace evidente que el actuar político de las mujeres en estas obras es igual al de los hombres, siendo, eso sí, algo más restringido en lo que a su duración y alcance se refiere.

35. Gerhard Poppenberg, «Política del amor. Los afectos y el poder en algunos dramas de Calderón», Anuario calderoniano, 2011, 4, pp. 283-295, p. 284. 
